\title{
EL DILEMA DE JORGENSEN: \\ LA BÚSOUEDA DE LOS FUNDAMENTOS \\ SEMÁNTICOS PARA LOS IMPERATIVOS
}

JORGENSEN'S DILEMA:

THE QUEST FOR SEMANTIC FOUNDATIONS OF IMPERATIVES

Miguel A. León Untiveros*

\section{RESUMEN}

En este trabajo atacamos el cuerno 2 del dilema de Jørgensen (tesis prohibitiva), con la idea de así fortalecer el cuerno 1 (tesis permisiva). Asimismo, exploramos parcialmente la idea de una solución sintáctica tomando como punto de partida que los imperativos carecen de valor de verdad.

\section{PALABRAS CLAVE}

Dilema de Jørgensen, lógica de imperativos, naturaleza de la lógica, pluralismo lógico, consecuencia lógica.

\begin{abstract}
In this paper we attack horn 2 of the Jørgensen's dilemma (prohibitive thesis), so we enforce horn 1 (permissive thesis). Also, we explore partially the idea of a syntactical solution for a logic of imperatives based on the fact of the lack of truth value of imperatives.
\end{abstract}

\section{KEY WORDS}

Jørgensen's dilemma, imperative logic, nature of logic, logical pluralism, logical consequence. 


\section{Jørgensen's dilemma.}

In 1938, the positivist philosopher, Jørgen Jørgensen, proposed a dilemma about the logic for imperatives ${ }^{1}$ despite Poincaré's claim who considered it possible (Poincaré, 1913). This dilemma has two horns: one, is, according to Poincaré, that there is a logic of imperative reasoning, where the major premise is in imperative mood and the minor premise is in indicative mood (we call it Horn 1, also permissive thesis). On the other hand, the second horn (Horn 2, also prohibitive thesis) says that because of imperative sentences lack of truth value and logic only deals with propositions (which have truth value), there is no a logic for imperatives.

Jørgensen's dilemma has received a lot of attention especially in the question of truth value of imperatives. And probably the most reasonable answer is the (almost obvious) lack of truth value of imperatives ${ }^{2}$. We think that even the lack of truth value of imperative, the reasons by which Jørgensen formulate horn 2 are not tenable anymore, in the light of the current situation of modern logic.

\section{Reasons for Horn 2.}

In (1938) and (1999 [1938]), Jørgensen presents the reasons by which he accepts Horn 2. First, only sentences which are capable of being true or false can function as premises or conclusions in an inference, and second, according to the logical positivist testability criterion of meaning, imperative sentences must be considered meaningless. These reasons presuppose a state of logic which were current for logical empiricism. Theses presuppositions are:

- Unity of logic.

- The hegemony of classical logic.

- Classical logical consequence.

- The only logic to give an account of reason is classical logic.

- The relation between logic and reason is unilateral in favor of logic.

Our aim is to attack these presuppositions and weaken Horn 2, such that the feasibility of Horn 1 will increase.

\section{(1) A plurality of logics.}

In the current situation of logic, the real realm is given by the classical and non-classical logics, especially deviant logics. To explicate the diversity let us give the following and provisional definition of classical logic:

A logical system is an ordered pair $\langle\mathrm{L}$, Q), where

$\mathrm{L}$ : is the language which has a vocabulary, rules for well-formed formulae and semantics, and,

$Q:$ is the rules of inference.

Thus, a system of classic logic is a structure $\langle\mathrm{L}, \mathrm{Q}\rangle$, with the following properties

1 The sense of imperative is not uniform, in this work we understand it in the way used by (Rescher, 1966), i.e., as a command.

2 Some scholars claim that imperative has truth value, if we formulate it in terms of deontic possible worlds, v.g., (Hintikka, 1971), (Stelmach $E$ Brozek, 2006, pp. 31-33), but this is not the place where to analyze it. However, we must say that using this modal approach of imperatives, we change the sense of imperative sentences. If we accept that an imperative sentence has a truth value function, then we have to admit that this imperative sentence is describing some deontic (ideal) state of affairs, and this is contrary to the original sense of an imperative sentence, by which the agent pretends to promote a change in the world, from the current one to another one (a potential and ideal one). Uttering an imperative sentence is a specific kind of act of speech and it is different from uttering an indicative sentence, by which the agent describes her current world. 


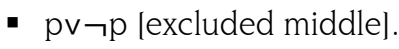

- $\mathrm{p} \equiv \mathrm{p}$ [identity].

- $\neg(\mathrm{p} \wedge \neg \mathrm{p})$ [non contradiction].

- $((\Sigma \subseteq \Delta) \wedge(\Sigma \vdash \Gamma)) \Rightarrow(\Delta \vdash \Gamma)$ [monotony]. Naively, monotony says that no matter what else we learn, we must conclude the same proposition.

A non-classical system of logic (i.e., deviant logics) is one that violates, at least, one of these properties (even partially).

Some logical systems deviate from excluded middle, and thus they form the family of polyvalent (also, multivalent) logics (which include fuzzy logics). In this kind of logics, a proposition could not be only either true or false, in a trivalent semantics, this could be neither true nor false. In a general way, the semantics of this kind of logics can be $n$-valent where $n$ is a natural real number $(n \in \mathbb{R})$ and $n$ is a number in the interval $[0,1]$, therefore, a proposition can take infinitely many values, between truth (1) and false (0).

Other deviant logical systems arise from violation of non-contradiction principle: this family is called paraconsistent logics. In this logic also fails the principle of explosion: $\mathrm{P}, \neg \mathrm{P} \vdash \mathrm{Q}$ (ex falso quodlibet sequitur). If a logical system $\boldsymbol{\mathcal { L }}$ distinguishes between two types of negation, say, $\neg, \sim$, then $\boldsymbol{L}$ can be paraconsistent for one of these negations, for example, $\neg$, and not so for the other one, $\sim$.

The next family of deviant logics is non-reflexive logics, recently proposed by Newton da Costa and his collaborators ${ }^{3}$. This logic violates identity principle and belongs to the larger family of quantum logics, which try to account the interpretation of quantum mechanics, where there are subatomic particles for which do not correspond the idea of identity (da Costa, Krause, Becker Arenhart, E Schinaider, 2012, págs. 85-88).

There is another family of logics called non-monotonic logics. In this systems fails monotonicity, and there is no guarantee for the conclusion, which can be changed if we add some other different premises.

There are other families of logics (v.g., intuitionistic logics, etc.), but the indicated ones are enough to show that logics is not a unique notion, and by no formal means we are able to give an account of its unity (Gabbay D. M., 2014), (Aliseda, 2014) without metaphysic commitments (León Untiveros, 2014).

Another remark: logics does not work anymore only with the Aristotelian bivalent truth value. As we see above, for example, multivalent logics deals with propositions which are neither true nor false. And, ironically, this is the case of imperatives. Therefore, its lack of bivalent truth value is not a real reason to reject a logic for imperatives.

\section{(2) ¿Hegemony of classical logic?}

As we said before there are two Jørgensen's papers with the same subject: one in English entitled "Imperatives and Logic" and the other in Danish "Imperativer og Logik", which means the same in English, even though both of them were issued in the same year, 1938, however, they are different by its content ${ }^{4}$. In his Danish paper, Jørgensen mentions modal logic only to discard it (Jørgensen, 1999

3 Cf. (da Costa E Bueno, 2009), (da Costa, Krause, Becker Arenhart, E Schinaider, 2012).

4 We took notice of this very important information from (Alarcón Cabrera, 1999), the Danish paper is partially translated into Spanish by Erling Strudsholm, Amedeo G. Conte and Carlos Alarcón Cabrera (Jørgensen, 1999 [1938]). 
[1938], p. 211 ), this strategy is fundamental for his argumentation in favor of Horn 2. This implicates hegemony of classical logic over non-classical logic. Is this Jørgensen's content tenable nowadays? By 1938, C.I. Lewis and C.H. Langford (1932) have proposed a system of modal logic, and since the end of the nineteenth century many-valued (or, multivalued) logics has been proposed by the Scotsman High McColl (1837-1909), the American Charles Sanders Peirce (1839-1914), the Russian Nicolai A. Vasil'év (1880 1940) and the Polish Jan Łukasiewicz (1878- 1956) ${ }^{5}$.

However, empiricist positivists were very influenced by David Hilbert's metamathematics (Echeverría, 1998, pp. 53-54), (Milkov, 2013, pp. 20-24), which can be summarized by Hilbert's dictum: "in mathematical matters there should be in principle no doubt; it should not be possible for half-truths or truths of fundamentally different sorts to exist." (Hilbert, 1996 [1922], p. 1117). For Hilbert, the axiomatic method does not need other laws of logic apart of Aristotelian ones (Hilbert, 1967 [1925]).

In the current situation of logic, there is no serious way to claim the hegemony of classical logic against deviant logics. The recent proposal, like Graham Priest's ones, (2003), (2006, pp. 194-209), fails, as showed by (Estrada-González, 2009) and (León Untiveros, 2014). As we said in our indicated paper, the geometric analogy as an argument in favor of the unity of logic is not tenable, because of in logic it does not occur as in geometry in which the formal relationship between geometries (Euclidean and non-Euclidean) is ontologically neutral. There is an ontological commitment of logic. The idea of a syntactic intersection of Priest
(2003), (2006, pp. 194-209) or the a priori common elements idea, are not effective arguments in favor of geometric analogy, but on the contrary, they are against geometric analogy.

On the other hand, it can be seen that multivalent logics is a generalization of classical logic (especially, in its semantics, because it goes from a bivalency to an $n$-valency, where $n \geq 2$ ). And, the same can be said of modal logic, where modal logic is a generalization of classical logic (Popkorn, 1994). Despite of these facts, we do not mean that we must give up classical logic, mostly because it is the logic for mathematics, even though not for ordinary language.

\section{(3) A non-classical concept of logical consequence.}

Jørgensen says that the relation between the premises and the conclusion of an argument is a logical consequence one, by which he understand "the conclusion follows logically from the premises (that is, it is logical consequence of premises) if and only if it is excluded the possibility that the premises are true and the conclusion is false" (Jørgensen, 1999 [1938], p. 211). This is the classical concept of logical consequence developed by Tarski (1983 [1935]).

However, since the works of Dov M. Gabbay (1985) and on, the concept of logical consequence has changed, in order to give a proper account of the use of arguments in Artificial Intelligence and Computer Science. Thus, it has appeared a new property for logical consequence, and this is known by non-monotonicity. This name is not much appropriate because it could give the misleading idea of a mere

5 For a beautiful history of many-valued logic see (Rescher, 1969). 
lack of monotonicity ${ }^{6}$, but this is not the case. In the logical literature, there are, at least, two non-classical notions of monotonicity ${ }^{7}$. Let us see,

\begin{tabular}{|l|l|l|}
\hline Classical logic & Classical Monotony & $((\Sigma \subseteq \Delta) \wedge(\Sigma \vdash \Gamma)) \Rightarrow(\Delta \vdash \Gamma)$ \\
\hline \multirow{2}{*}{$\begin{array}{l}\text { Non-monotonic } \\
\text { logics }\end{array}$} & Rational Monotony ${ }^{1}$ & $((\Delta \vdash \neg \varphi) \wedge(\Delta \vdash \psi)) \Rightarrow((\Delta \wedge \varphi) \vdash \psi)$ \\
\cline { 2 - 3 } & Cautious Monotony & $((\Delta \vdash \varphi) \wedge(\Delta \vdash \psi)) \Rightarrow(\Delta \wedge \varphi) \vdash \psi)$ \\
\hline
\end{tabular}

Roughly, classical monotony says that no matter what else we learn, we must conclude the same proposition. Therefore, the conclusion is guaranteed. This warrant only needs that the original set of premises $\Sigma$ is included in another set $\Delta$, and nothing else matters.

On the contrary, for example, with a cautious monotony, the conclusion $\psi$ is guaranteed if and only if from the set of premises $\Delta$ follows logically $\varphi$ and $\psi$, independently.

For example, let us consider a set of premises, say, $\Sigma$, from which follows a conclusion $\psi$. Then, we learn something else different, say $\varphi$. If we work with classical monotony, we must conclude that from $\Sigma$ and $\varphi$ follows $\psi$, that is,

$$
((\Sigma \vdash \psi) \wedge \Sigma \subseteq\{\Sigma, \varphi\}) \Rightarrow\{\Sigma, \varphi\} \vdash \psi
$$

In classical logic, it does not matter the content of the new information, $\varphi$. Even, this could be contrary to $\psi$, i.e., $\psi$, and from a classical logical point of view the conclusion $\psi$ follows correctly from the premises. This is because classical monotony requires only one condition: that the original set of premises should be a subset of the new one, i.e., $\Sigma \subseteq\{\Sigma, \varphi\}$.
In the case of cautious monotony, there is a more restricted condition, which requires that the new premise $\varphi$ should be the logical consequence from the original set of premises $\Sigma$, i.e., $\Sigma \vdash \varphi$.

\section{(4) The fluid relationship between reason and logic.}

In textbooks, the defined aim of logic is to evaluate correctness of any argument, and it is done, mostly, by classical or mathematical logic, thus (Copi, Cohen, $\varepsilon$ McMaho, 2014) say: "Logic is the study of the methods and principles used to distinguish correct from incorrect reasoning", and chapters about analogy and induction are considered as a kind of argument which validity cannot be settled by logical means.

Once we accept this conception of logic, we must content that any argument (or reasoning) which do not fulfill this restriction, is not logical or at most it is just a fallacy, despite its plausible appearance.

Underlying this conception of the task of logic, there is the idea that logic has a prior status against reason, this tradition or paradigm can be traced back to Kant. In the preface of the second

6 This remark was noted by professor Dr. Marino Llanos in personal conversation.

7 See (Antonelli, 2005) among others. 
edition of Critique of Pure Reason, the German philosopher says: "But I can think whatever I like, as long as I do not contradict myself, i.e., as long as my concept is a possible thought," (Kant, 1998 (1789), pp. 115, Bxxvi). However, this is no more tenable in the light of current logic (especially, because of the case of paraconsistent logics).

Nowadays the relation between reason and logic is fluid, a kind of mutual and progressive adjustment ${ }^{8}$. That is the lesson caused by the discovery of deviant logics. So, when we have to evaluate the correctness of a reasoning, classical logic is not the only option, there are a bunch of logical alternatives, each one with a set of special features that must be evaluated according to our goals, that is, the features of the specific reason we want to emphasize, idealize, and analyze.

Therefore, is not tenable anymore the thesis that logic is prior before which a reasoning must be judge, logic is not a tribunal for reason. That means the relation between them are bilateral, logic and reason interact mutually, without priority. This situation arises the question about reason and its relation to logic, however, this is not the place to try this very interesting subject. Following Miró Quesada Cantuarias, we only can say that logic is like reins which prevent reason unbolts itself (Miró Quesada Cantuarias, 1963).

\section{Features of imperative reasoning.}

Legal and moral reasoning have specific features which make them different from mathematical reasoning. The most important are: graduality, inconsistency, and defeasibility. Graduality is given by the notions like light, moderate and serious interference with rights (Alexy, 2003) ${ }^{9}$. Inconsistency is given by conflict of moral duties ${ }^{10}$. And, defeasibility is given by legal prescription of extinction of legal action because the occurrence of a lapse of time, such that before that, it could be drawn as the conclusion that someone is guilty, but this could be not the case anymore after the occurrence of a lapse of time.

This three features of legal and moral reasoning are very important, and sadly, classical logic could not provide an adequate answer (Horty, 1997), (Ausín, 2005).

Defeasibility is better dealt by nonmonotonic logic. Contrary to what some important legal scholars claim, for example (Alexy, 2000), classical logic is not a suitable alternative for legal reasoning. We will see closely the example given by Alexy to show that classical logic is adequate to modelling legal reasoning:

Let propositions $p, q, r$ be:

$p$ : Bob kills Peter,

$q$ : Bob goes to jail,

$r$ : Bob acts in self-defence.

8 (Bôcher, 1905, pp. 119-120), (Goodman, 1983), (Bunge, 1996, p. 68), (Gabbay E Woods, 2008), among others.

9 This feature can be dealt by fuzzy logic (Mazzarese, 1993), (Mazzarese, 1999), (Miró Quesada Cantuarias, 2000), (Puppo, 2012), among others

10 Thus, the famous Sartre's example: a French student during the Second World War who felt for reasons of patriotism and vengeance (his brother had been killed by the Germans) that he ought to leave home in order to join the Free French, but who felt also, for reasons of sympathy and personal devotion, that he ought to stay at home in order to care for his mother (Sartre, 1966 [1946], pp. 35-37). Horty proposes a non-monotonic solution for this case (Horty, 1997). 
The premises are:

$$
\begin{array}{ll}
\text { 1. } & p \Rightarrow q \\
\text { 2. } & p \wedge r \Rightarrow q \\
\text { 3. } & p \wedge r
\end{array}
$$

From here, by classical laws of logic, we derive the following, as Alexy does (Alexy, 2000).

\section{4. $q \Rightarrow \neg(p \wedge r) 2$, Law of Contraposition 5. $\neg 9$ 3, 4, Modus tollens}

Here is where Alexy stops. He believes it is enough and he gets what we consider just a correct conclusion, that is, $\neg q$, which means "Bob does not go to jail". However, from a logical point of view, the set of consequences $(\mathrm{C} n)$ from a set of premises (A) are the whole conclusions (or propositions, $\chi$ ) which logically follows from the premises, that is, $\operatorname{Cn}(\mathrm{A})=\{x \mid$ Ar $x\}^{11}$. Thus, we can obtain

\section{6. $p$ 3, Simplification \\ 7. 9 1,6 Modus Ponens \\ 8. $q \wedge q$ 5,6 Adjunction. [ABSURD]}

Line 8 is an absurd (i.e., a contradiction). And, this contradiction is necessarily obtained because of the use of classical logic. However, contradictions could be dealt if we use nonmonotonic logics. Let us see this very roughly:

The premises are:

$$
\begin{array}{ll}
\text { 1. } & p \Rightarrow q \\
\text { 2. } & p \wedge r \Rightarrow q \\
\text { 3. } & p \wedge r
\end{array}
$$

We introduce here the revision operator *

At first, we have an initial set of set of premises

$$
K=\{1,2\}
$$

But then, it happens 3, the question is to avoid contradiction if we add 3 to $\mathrm{K}$. This operation of revision is formulated as $\mathrm{K} * 3$

By definition

$$
K^{*} 3:=(K \div q)+3^{12}
$$

The result is

Then, we infer

$$
\mathrm{K}^{*} 3=\{2,3\}
$$

$$
\text { 4. } 92,3 \mathrm{MP} \text {. }
$$

Thus, we do avoid contradiction and we have used correctly a non-classical concept of logical consequence.

\section{IV. ¿A mere syntactical solution?}

In his Danish paper, Jørgensen just mentions a possible syntactic solution. This kind of proposal has been given by Mario Bunge (1989, p. 301), where he introduces two axiological inference rules: modus volens and modus nolens ${ }^{13}$.

We want to address this question: is standard deontic logic a syntactical solution? Its axiomatization looks like the following ${ }^{14}$ :

Deontic operators: $\mathrm{O}$ (obligated), P (permitted), F (forbidden).

We take as the primitive concept: $\mathrm{O}$. The other deontic operators are defined in the following way:

$$
\begin{aligned}
& \mathrm{Pp}:=\bigcirc \mathrm{p} \\
& \mathrm{Fp}:=\bigcirc \mathrm{p}
\end{aligned}
$$

Thus, the axiom schemes are:

11 Cf. (Makinson D. , 2005, p. 4).

12 " $\div$ " means the operation of contraction, and " + " means the operation of expansion. For details see (Hansson, 1999), for philosophical applications of belief logics see (Olsson E Enqvist, 2011).

13 In logical literature there is an interesting question about the admissibility of inference rules, cf. (Rybakov, 1997), but this is not the place to analyze the kindness of this proposals.

14 We follow (Ausín, 2005, pp. 40-41). 
(A0) All tautologies from propositional calculus.

(A 1) $\mathrm{Op} \Rightarrow \mathrm{Pp}$ [Bentham's o Leibniz's Law]

$$
\text { (A2) } \bigcirc(p \Rightarrow q) \Rightarrow(O p \Rightarrow \bigcirc q)
$$

[K-deontic axiom]

And the inference rules are:

(MP) $\mathrm{p} \Rightarrow \mathrm{q}, \mathrm{p} / \mathrm{q}$

(DNR $^{15}$ ) $-\mathrm{p} / \mathrm{Op}(\mathrm{O}$-necessitation)

Standard deontic logics has a formal semantics, but here we focus only on its syntactic side ${ }^{16}$.

The underlying logic beyond this axiomatization is the so-called Dubislav convention ${ }^{17}$, which states

(DC) An imperative $F$ is called derivable from an imperative $\mathrm{E}$ if the descriptive sentence belonging to $\mathrm{F}$ is derivable with the usual methods from the descriptive sentence belonging to $\mathrm{E}$, whereby identity of the commanding authority is assumed (Dubislav, 1938).

Let !A, !B be imperatives, its corresponding descriptive sentences are A, B. Dubislav convention has the

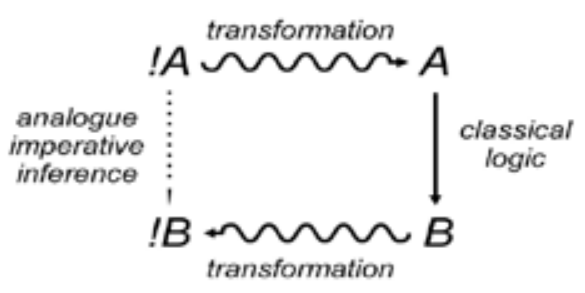

following graphical shape (Hansen, 2008, p. 9):

The transformation !A $m$ A reflects the analogy between norms and normpropositions in order to use classical logic. This is presupposed in standard deontic logic, and it caused many shortcomings like the contrary-to-duty paradox ${ }^{18}$, Ross' paradox $^{19}$, among others ${ }^{20}$.

The relation between $\mathrm{A}, \mathrm{B}$, is of logical consequence, $\mathrm{A}-\mathrm{B}$, i.e., there is a finite sequence of statements where each statement in the list is either an axiom or the result of applying a rule of inference to one or more preceding statements. The final statement is the conclusion of the proof.

The transformation! $\mathrm{A} \rightsquigarrow \mathrm{A}$ is a subject of the deontic necessitation rule, which

15 Deontic necessitation rule.

16 As we said before, the semantics for standard deontic logic is the so-called "possible worlds" semantics. The model for this case is the triple

Where

$$
\mathrm{M}=\langle\mathrm{W}, \mathrm{R}, \mathrm{V}\rangle
$$

(i) W is a non-empty set (heuristically, of 'possible worlds' or 'possible situations').

(ii) $\mathrm{R} \subseteq \mathrm{WxW}$ (a binary relation on W, heuristically, of "deontic alternativeness" or "copermissibility").

(iii) $\mathrm{V}$ is an assignment, which associates a truth-value 1 or 0 with each ordered pair $(p, \chi)$ where $p$ is a proposition letter and $x$ is an element of $\mathrm{W}$; that is, V: Prop $\mathrm{xW} \rightarrow\{1,0\}$.

For details, see (Åqvist, 1984).

17 After the German logician, philosopher of science, logical empiricist, Walter Dubislav (1895 - 1937).

18 This paradox states:

1. It ought to be that a certain man goes to assistance of his neighbors.

2. It ought to be that if he does go, he tells them he is coming.

3. If he does no go, then he ought not to tell them he is coming.

4. He does not go.

Therefore, he ought to come and he ought not to come.

19 This paradox states: take the imperative 'Post the letter!' then use this method to derive the imperative 'Post the letter or burn it!'

20 For a recent discussion of this matter see (Hilpinen \& McNamara, 2013) and (Navarro E Rodríguez, 2014), for a comprehensive list of problems in deontic logic see (León Untiveros, 2015) 
states by decree the transformation of a descriptive sentence into an imperative sentence.

The trick question is the notion transforming a descriptive sentence from an imperative F. DC does not explain how we can proceed formally. Thus, the notion of transforming is not clear.

Besides, DC does not explain how we can derive (transform) an imperative $\mathrm{E}$ from a descriptive sentence. This question is the famous is-ought problem, raised by David Hume, and standard deontic logic solves it by decree.

On the other hand, as we saw before, Jørgensen considers "the conclusion follows logically from the premises (that is, it is logical consequence of premises) if and only if it is excluded the possibility that the premises are true and the conclusion is false" (Jørgensen, 1999 [1938], p. 211). This is the semantic conception of logical consequence (also called modeltheoretic), but there is another account of logical consequence, a syntactical one (also called proof-theoretic) which was first proposed by Gerhard Gentzen in 1935, (Gentzen, 1969 [1935]), according to which the meaning of a logical connective is defined by its introduction rules (while the elimination rules are justified by respecting stipulation made by the introduction rules). Thus, a formula $B$ is a consequence of another $A$ by virtue of the inferential meaning of logical connectives (Caret $E$ Hjortland, 2015, p. 8). So, we do not need any valuation of truth. Some scholars, like
(Read, 2015), even claim that analytically valid arguments may yet fail to be truth preserving ${ }^{21}$.

Therefore, the syntactical line opened by the proof-theoretic conception of logical consequence represents an alternative possibility for a (maybe) suitable account of imperative reasoning. Thus, we think Horn 2 is not tenable anymore, at least, it is not as strong as it was in 1938.

\section{REFERENCES}

Alarcón, C. (1999). "Imperativos y lógica en Jørgen Jørgensen". En: Isegoría (20), 207-210.

Alexy, R. (2000). Henry Prakken (1997), Logical Tools for Modelling Legal Argument. A Study of Defeasible Reasoning in Law. Argumentation, 14, 66-72.

Antonelli, G. A. (2005). Grounded Consequence for Defeasible Logic. Cambridge: Cambridge University Press.

Ausín, T. (2005). Entre la Lógica y el Derecho. Paradojas y conflictos normativos. México: Plaza y Valdés.

Bobbio, F. (1972). La lógica normativa: Balance de dos décadas de investigaciones y examen de sus posibilidades [Tesis]. Lima: Universidad Nacional Mayor de San Marcos.

21 Nowadays, there is an intense revision of the task of logical consequence because: (i) model-theoretic consequence preserves truth-in-a-model, but this a theoretic construct that is not necessarily a good model of truth simpliciter; (ii) with the popularity of many-valued logic it is commonplace to talk about preservation of designed values rather than just the truth value true; and (iii) it is not clear that consequence is best understood in terms of preservation of truth values, or at least not as preservation of truth values alone. Perhaps, consequence requires preservation of warrant, or a relevance relation between the content of the premises and the content of the conclusion, such as variable sharing (Read, 1988), (Restall, 2009), (Caret \& Hjortland, 2015, pp. 15-16). 
Bôcher, M. (1905). The fundamental conceptions and methods of mathematics. Bulletin of the American Mathematical Society, XI, 115-35.

Caret, C. R., E Hjortland, O. T. (2015). Logical Consequence: Its Nature, Structure, and Application. In C. R. Caret, E O. T. Hjortland (Eds.), Foundations of Logical Consequence (pp. 3-29). Oxford: Oxford University Press.

da Costa, N. C., Krause, D., Becker Arenhart, J. R., \& Schinaider, J. (2012). "Sobre uma fundamentação não reflexiva da mecânica quântica". En: Sientiae Studia, 10(1), 71-104.

da Costa, N., E Bueno, O. (2009). "Lógicas não-reflexivas". En: Revista Brasileira de Filosofía, 232, 181-96.

Dubislav, W. (1938). Zur U n b e gr ü n d barke i t d e r Forderamgssätze. Theoria, 3, 330-42.

Estrada-González, L. (2009). The Geometric Analogy and the idea of Pure Logic. In W. Carnielli, M. E. Coniglio, E I. M. Loffredo D'Ottaviano (Eds.), The Many Sides of Logic (pp. 17185). London: College Publication.

Gabbay, D. (1985). Theoretical foundations for non-monotonic reasoning in expert systems. In K. R. Apt (Ed.), Logics and Models of Concurrent Systems (pp. 439-457). Berlin Heidelberg New York Tokyo: Springer.

Gabbay, D. M. (2014). What is a logical system? An Evolutionary View: 19642014. In D. M. Gabbay, J. H. Siekmann, E J. Woods (Eds.), Handbook of the History of Logic (Vol. 9, pp. 41 132). Amsterdam et al.: Elsevier.
Gabbay, D., E Woods, J. (2008). Resource-origins of Nonmonotonicity. (H. Leitgeb, Ed.) Studia Logica, 8(1. Special Issue: Psychologism in Logic?), 85-112.

Hansen, J. (2008). Imperatives and Deontic Logic. On the Semantic Foundations of Deontic Logic. Leipzig: PhD dissertation Leipzig University.

Hansson, S. O. (1999). A Textbook of Belief Dynamics. Theory of Change and Database Updating. Dordrecht: Kluwer Academic Publishers.

Hilbert, D. (1967 [1925]). On the infinite. In J. van Heijenoort (Ed.), From Frege to Gödel. A source book in mathematical logic, 1979 - 1931 (J. van Heijenoort, Trans., pp. 367-392). Cambridge: University Harvard Press.

Hilbert, D. (1996 [1922]). The new grounding of mathematics. In W. Ewald (Ed.), From Kant to Hilbert: A Source Book in the Foundations of Mathematics (Vol. II, pp. 1115-34). Oxford: Oxford University Press.

Hintikka, J. (1971). Some main problems of deontic logic. In R. Hilpinen (Ed.), Deontic logic: Introduction and systematic readings (pp. 59-104). Dordrecht Boston - London: D. Reidel Publishing.

Horty, J. F. (1997). Nonmonotonic foundations for deontic Logic. In D. Nute (Ed.), Defeasible Deontic Logic (pp. 17-44). Dordrecht: Springer.

Jørgensen, J. (1938). Imperatives and Logic. Erkenntnis(7), 288-96.

Jørgensen, J. (1999 [1938]). "Imperativos y lógica”. En: Isegoría(20), 210-215. 
Kant, I. (1998 (1789)). Critique of pure reason (Second ed.). (P. Guyer, \& A. W. Wood, Trans.) Cambridge: Cambridge University Press.

León, M. (2014). "La analogía geométrica y la unidad de la lógica: Los compromisos ontológicos de la filosofía de la lógica". En: Analítica(8), 61-82.

León, M. (2015). El dilema de Jørgensen: Fundamentos semánticos de los imperativos. Inédito.

Makinson, D. (2005). Bridges from Classical to Nonmonotonic Logic. Milton Keynes: Lightning Source.

Mazzarese, T. (1993). Fuzzy Logic and Judicial Decision-Making. A new Perspective on the Alleged NormIrrationalism. Informatica e diritto, II(3), 13-36.

Milkov, N. (2013). The Berlin Group and the Vienna Circle: Affinities and Divergences. In M. Milkov, E V. Peckhaus (Eds.), The Berlin Group and the Philosophy of Logical Empiricism (pp. 3-32). Dordrecht: Springer.

Miró Quesada, F. (1963). Apuntes para una teoría de la razón. Lima: Universidad Nacional Mayor de San Marcos.

Miró Quesada, F. (2000). Ratio Interpretandi. Ensayo de hermenéutica jurídica. Lima: Fondo Editorial de la Universidad Inca Garcilaso de la Vega.

Poincaré, H. (1913). La Morale et la Science. In H. Poincaré, Dernières pensées (pp. 221-247). Paris: Ernest Flammarion.
Priest, G. (2003). On Alternative Geometries, Arithmetics, and Logics. A Tribute to Łukasiewicz. Studia Logica (74), 441-68.

Priest, G. (2006). Doubt Truth to Be a Liar. Oxford: Clarendon Press.

Read, S. (1988). Relevant Logic. A Philosophical Examination of Inference. Oxford: Basil Blackwell.

Read, S. (2015). Proof-Theoretic Validity. In C. T. Caret, \& O. T. Hjortland (Eds.), Foundations of Logical Consequence (pp. 136-158). Oxford: Oxford University Press.

Rescher, N. (1966). The Logic of Commands. London: Routledge $\varepsilon$ Kegan Paul.

Rescher, N. (1969). Many-Valued Logic. Vermont: Greg Revivals.

Restall, G. (2009). Logical Pluralism and the Preservation of Warrant. In S. Rahman, J. Symons, D. M. Gabbay, E J. P. van Bendegem (Eds.), Logic, Epistemology And The Unity Of Science (Vol. 1, pp. 163-174). Springer: Springer.

Tarsky, A. (1983 [1935]). On the concept of logical consequence. In A. Tarski, E J. Corcoran (Ed.), Logic, Semantics, Metamathematics. Indianapolis: Hackett Publishing Company. 
